This item was submitted to Loughborough's Research Repository by the author.

Items in Figshare are protected by copyright, with all rights reserved, unless otherwise indicated.

\title{
Assessing the dependence of surface layer atmospheric stability on measurement height at offshore locations
}

\section{PLEASE CITE THE PUBLISHED VERSION}

http://dx.doi.org/10.1016/j.jweia.2014.06.002

\section{PUBLISHER}

(C) Elsevier

VERSION

AM (Accepted Manuscript)

\section{PUBLISHER STATEMENT}

This work is made available according to the conditions of the Creative Commons Attribution-NonCommercialNoDerivatives 4.0 International (CC BY-NC-ND 4.0) licence. Full details of this licence are available at: https://creativecommons.org/licenses/by-nc-nd/4.0/

\section{LICENCE}

CC BY-NC-ND 4.0

\section{REPOSITORY RECORD}

Argyle, Peter, and Simon J. Watson. 2019. "Assessing the Dependence of Surface Layer Atmospheric Stability on Measurement Height at Offshore Locations". figshare. https://hdl.handle.net/2134/17729. 


\title{
Assessing the Dependence of Surface Layer Atmospheric Stability on Measurement Height at Offshore Locations
}

\author{
P. Argyle a, S. J. Watson ${ }^{\text {a* }}$ \\ a CREST, School of Electronic, Electrical and Systems Engineering, Loughborough University, \\ Loughborough, UK, LE67 5AH \\ ${ }^{*}$ Corresponding author. Tel.: +44 1509635348 \\ E-mail address: s.j.watson@lboro.ac.uk
}

\begin{abstract}
Incorporating atmospheric stability into wind resource assessment modelling is becoming more common. This study investigates some of the challenges associated with calculating stability in the offshore environment. Data are analysed from meteorological masts FINO1 and FINO3 in the German North Sea using measurements at three different heights and results show significant differences in stability assessment depending on which combination of heights are used. All methods show the North Sea to be very unstable for the majority of the time, although by ignoring wind and thermal data from below $50 \mathrm{~m}$, the atmosphere appears more stable, indicating the presence of a marine internal boundary layer. Even $80 \mathrm{~km}$ out to sea, it is suggested FINO3 still feels the effects of land, and it is clear the height of the atmospheric surface layer effects wind speed measurements under certain conditions.
\end{abstract}

\section{Keywords}

Atmospheric stability; Monin-Obukhov similarity theory; FINO1; FINO3

\section{Introduction}

During the process of resource assessment for a new wind farm, it is common practice to erect at least one meteorological mast extending to proposed turbine hub height to obtain climate information suitable for the prediction of future production yields. Since taller masts are more expensive, wind speeds above this height are estimated using a form of logarithmic profile. It is well documented ([1] and [2]) that atmospheric stability significantly alters the wind shear as well as the height of the surface layer (SL) and therefore accurate predictions of the wind resource above hub height usually depend on the reliability of stability calculations used for equation 1 below, where $u_{z}$ is velocity at height $z$ above the sea surface, $u_{*}$ is the friction velocity, $k$ is the von Kármán constant, $z_{0}$ is the sea surface roughness and $\psi_{m}$ is the stability function which depends on height and the Obukhov length $L$.

$$
u_{z}=\frac{u_{*}}{k}\left[\ln \left(\frac{Z}{z_{0}}\right)-\psi_{m}\left(\frac{Z}{L}\right)\right]
$$


Besides knowledge of a site's wind resource above hub height, the frequency distribution of atmospheric stability is becoming increasingly valuable within large offshore farms as [3] directly links it to the magnitude of power deficits from wake losses. As farms grow in size, the importance of accurate wake loss prediction (and thus analysis of stability conditions) increases. For offshore farms, the cost of a met mast is a significant initial expenditure and therefore, resource modelling is desirable to reduce the number of masts required to obtain velocity profiles throughout a large development area [2] whilst also predicting how turbine wakes will affect production yields. To accommodate the prevailing non-neutral marine atmospheres described in [4] and [5], wake modelling software designers are starting to include basic stability functions, [6] and [7].

To verify the accuracy of models, a high quality source of meteorological data is required, to define the local stability conditions and assess the model results.

However, there are many ways to calculate stability, (some of which are compared in [8] and [9]) and studies often use the method effectively dictated to them by available data. This inconsistency not only makes site comparison difficult, but also relies on assumptions made when using the Monin-Obukhov Similarity Theory (MOST), notably, that the virtual potential temperature (VPT) described by equation 2 , follows a linear profile within the SL.

$$
\theta_{v}=\theta\left(1+0.61 r-r_{L}\right)
$$

Where $\theta$ is the potential temperature, $r$ is the mixing ratio of water vapour and $r_{L}$ is the mixing ratio of liquid water in the air. This assumption allows thermal measurements to be taken at any height on a mast and be considered sufficient to determine the stability conditions from the sea surface to the top of the SL. However, the thermal profile is not linear; changes in surface heat capacity (for example land to sea) or the development of internal mixing layers throughout the day can significantly change the profile [10]. Offshore, this is most likely to be caused by thermal differences between air and sea [1].

Whilst [11] shows there is good agreement between stability calculations at three heights using sonic anemometers to calculate the corrected surface heat fluxes of marine fetches at FINO1; sonic anemometers are not standard equipment installed by the wind industry. Remote sensor measurements of the sea skin temperature required for the bulk method of calculating $L$ [12] are rarely available and bulk temperature measurements within $2 \mathrm{~m}$ of the surface have to be carefully adjusted [13] and calibrated with air measurements. Using the gradient between two air temperatures is not only more representative of physical conditions experienced by turbines; masts are often suitably instrumented at multiple heights and [14] proposes it to be the most promising classification method. Therefore, this study investigates the implications of measurement height in relation to MOST, using the gradient Richardson number $\left(R_{i}\right)$ to infer $L$, via equations 3 and 4 below:

$$
L=\left\{\begin{array}{crl}
\left(\frac{z^{\prime}}{R i}\right) & R i<0 & \operatorname{Ri}\left(z^{\prime}\right) \\
\frac{z^{\prime}(1-5 R i)}{R i} & 0<R i<0.2 & =\frac{\frac{g}{\bar{T}}\left(\frac{\Delta \bar{\theta}_{v}}{\Delta z}\right)}{\left(\frac{\Delta \bar{u}}{\Delta z}\right)^{2}}
\end{array}\right.
$$


Where $z^{\prime}$ is the height where the calculated gradient Richardson number is valid, estimated via $z^{\prime}=\left(z_{1}-z_{2}\right) / \ln \left(z_{1} / z_{2}\right), \bar{T}$ is a reference atmospheric temperature, $\Delta \overline{\theta_{v}}$ is the difference in VPT between $z_{1}$ and $z_{2}, g$ is gravitational acceleration, $\Delta u$ is the difference in wind speed and $\Delta z$ is the height difference between the two measurements at heights $z_{1}$ and $z_{2}$.

\section{Datasets}

For this study, data were analysed from the offshore meteorological masts in the German North Sea: FINO1 and FINO3. Table 1 compares the instrumentation at each mast suitable for atmospheric stability analysis.

Table 1 Heights of instruments used to measure the five variables nessecary. An asterix implies the use of a sonic anemometer whilst numbers in brackets imply multiple instruments at specific heights.

\begin{tabular}{|c|c|c|}
\hline Variable measured & Heights at FINO1 [m] & Heights at FINO3 [m] \\
\hline Wind Speed & $33,40,40^{*}, 50,60,60^{*}, 70$, & $30,40,50(3), 60,60^{*}, 70(3)$, \\
& $80,80^{*}, 90,100$ & $80(2), 90(3), 100,100^{*}, 106$ \\
\hline Wind Direction & $33,40^{*}, 50,60^{*}, 70,80^{*}, 90$ & $30,60,60^{*}, 80,100,100^{*}$ \\
\hline Air Temperature & $30,40,50,70,100$ & $29,55,95$ \\
\hline Air Humidity & $33,50,90$ & $29,55,95$ \\
\hline Air Pressure & 20,90 & 23,94 \\
\hline
\end{tabular}

Data from the FINO1 mast are from the beginning of January 2004 to the end of December 2007 (before the construction of the nearby wind farm Alpha Ventus), whilst the FINO3 data are from mid-September 2009 to the end of October 2011. Each datum represents the average across a ten minute event. In order to satisfy the assumptions of MOST, both datasets have been filtered to ensure homogeneous atmospheric conditions, although no adjustment has been made to account for the height of the SL. Values of wind speed, direction and temperature at key heights for each event were compared to those for the following event and previous two events; the atmosphere was considered to be in a non-homogeneous state if the wind speed varied by more than $20 \%$, direction by more than $15^{\circ}$ or temperature by $0.5^{\circ}$.

Whilst both masts are equipped with sonic anemometers, masts deployed by the wind industry normally rely on cup anemometers as their lower frequency sampling rate is considered sufficient for measuring the mean wind speed. Their greater deployment also provides more options when selecting heights for this study, compared to sonic anemometers, thus providing a more complete picture of the SL. (One conclusion from [11] was that the sonic anemometer heights are not low enough to represent the near surface conditions, particularly in stable conditions). At FINO3 there are varying numbers of cup anemometers at each height. For consistency between heights therefore, only the speed data from instruments located on booms facing direction $345^{\circ}$ were used. This also increases the consistency between mast datasets as FINO1 only has one cup anemometer at each height, although it increases the risk of mast shadow effects. To counter this, both datasets were analysed for mast shadow by comparing ratios of speed measurements from the cup and sonic anemometers at $80 \mathrm{~m}$ and $100 \mathrm{~m}$ at FINO1 and FINO3 respectively against wind directions at the top of each mast. It was deduced that the cup 
anemometer booms extend from the masts at $135^{\circ}$ and $350^{\circ}$ respectively and it is assumed booms at other heights are consistent with these, with mast shadow affected data entries filtered accordingly. A sector of $40^{\circ}$ was considered affected by mast shadow at FINO1 in contrast to only a $16^{\circ}$ sector at FINO3.

At both locations, atmospheric pressure was measured at two heights. However, because of the low quality of the readings taken at 90m at FINO1 and the two pressure measurements at FINO3 having a correlation coefficient of 0.999 whilst differing by less than one percent of the absolute value; all required values for pressure from FINO1 were assigned those measured at $20 \mathrm{~m}$. To maintain consistency between datasets, pressure readings taken at $23 \mathrm{~m}$ at FINO3 were used accordingly, (thus ignoring the measurements taken at $94 \mathrm{~m}$ ). The data have been split and analysed as six case studies, as shown by Table 2 to show the dependence of $L$ on $Z$ '.

Table 2 Height in metres of temperature, humidity and wind speed measurements for each case study. tTemperature at $90 \mathrm{~m}$ was estimated via linear interpolation between $70 \mathrm{~m}$ and $100 \mathrm{~m}$.

\begin{tabular}{|c|c|c|c|c|c|c|c|c|}
\hline \multirow{2}{*}{ case } & Met & \multirow{2}{*}{$z^{\prime}$} & \multicolumn{2}{|c|}{ Temperature Height } & \multicolumn{2}{c|}{ Humidity Height } & \multicolumn{2}{c|}{ Wind Speed Height } \\
\cline { 5 - 9 } & Mast & & Low & High & Low & High & Low & High \\
\hline A & FINO1 & 40.91 & 30 & 50 & 33 & 50 & 33 & 50 \\
\hline B & FINO1 & 68.05 & 50 & $90^{\dagger}$ & 50 & 90 & 50 & 90 \\
\hline C & FINO1 & 56.81 & 30 & $90^{\dagger}$ & 33 & 90 & 33 & 90 \\
\hline D & FINO3 & 39.15 & 29 & 55 & 29 & 55 & 30 & 50 \\
\hline E & FINO3 & 68.05 & 55 & 95 & 55 & 95 & 50 & 90 \\
\hline F & FINO3 & 54.61 & 29 & 95 & 29 & 95 & 30 & 90 \\
\hline
\end{tabular}

\section{Results}

Having calculated Obukhov lengths for datasets A to $F$, they were binned by stability class to simplify analysis as shown in Table 3 . Whilst the definition of stability bins is often open to interpretation and varying their boundaries could alter results of any analysis, these definitions have been used previously by authors [1], [2] and [4].

Table 3 Classification of atmospheric stability. The abbreviations are used to refer to specific stability conditions in figures throughout this work.

\begin{tabular}{|c|c|c|}
\hline Atmospheric Condition & Definition & Abbreviation \\
\hline Very Stable & $0 \mathrm{~m}<\mathrm{L}<200 \mathrm{~m}$ & $\mathrm{VS}$ \\
\hline Stable & $200 \mathrm{~m}<\mathrm{L}<1000 \mathrm{~m}$ & $\mathrm{~S}$ \\
\hline Neutral & $1000 \mathrm{~m}<\mathrm{L}$ or $\mathrm{L}<-1000 \mathrm{~m}$ & $\mathrm{~N}$ \\
\hline Unstable & $-1000 \mathrm{~m}<\mathrm{L}<-200 \mathrm{~m}$ & $\mathrm{U}$ \\
\hline Very Unstable & $-200 \mathrm{~m}<\mathrm{L}<0 \mathrm{~m}$ & $\mathrm{VU}$ \\
\hline
\end{tabular}

Figure 1 shows that the distribution of stability classes is related to the heights at which the measurements are taken. For example, there is a significant difference in stability distribution when comparing cases $A$ and $D$ with cases $B$ and $E$, indicating that the marine air below $50 \mathrm{~m}$ is mostly very unstable whilst above $50 \mathrm{~m}$, there is greater stability. The difference in distributions above and below $50 \mathrm{~m}$ suggests an internal boundary layer may be present at both sites, with greater thermal and mechanical mixing processes than in the less turbulent air at potential hub heights. Significantly, FINO1 is located $45 \mathrm{~km}$ from shore whilst FINO3 is $80 \mathrm{~km}$ from the 
nearest shore (although roughly $60 \mathrm{~km}$ from the farm Horns Rev), so there is a significant fetch for these marine boundary conditions to develop and any coastal effects to dissipate. The distributions for $\mathrm{C}$ and $\mathrm{F}$ also show a strong bias towards very unstable conditions, similar to that of $A$ and $D$, indicating that the lower, more unstable atmosphere has greater significance than more stable conditions above, when calculating the overall stability, a result also concluded by [9]. Not shown in Figure 1 is that roughly $40 \%$ of analysed data for B and $E$ had to be filtered out as their corresponding gradient Richardson numbers were larger than the critical value, (taken as 0.2 as in [4], [5] and [8]) and thus removed. Less than $10 \%$ of the other datasets suffered this condition implying very stable events with low turbulence intensities are even more common at higher levels than shown for B and $\mathrm{E}$. As a result, any modelling for resource assessment using results from $\mathrm{C}$ and $\mathrm{F}$ (to benefit from the complete height of the masts) will primarily simulate the prevailing unstable conditions when in fact the future turbine rotors are likely to initially experience the more stable conditions displayed by $\mathrm{B}$ and $\mathrm{E}$, although wake rotation and turbulence is likely to increase mixing between the two layers. Caution is urged when attempting to translate these results to other offshore locations as results by [1] show stability distributions from four masts with more neutral and stable conditions. Whilst these differences can partially be explained by proximity to shore, and therefore the averaging effects of stronger diurnal cycles observed by [1], none of their four masts measure parameters more than $50 \mathrm{~m}$ above the sea surface and so would be closest to Cases $A$ and $D$ in this work.

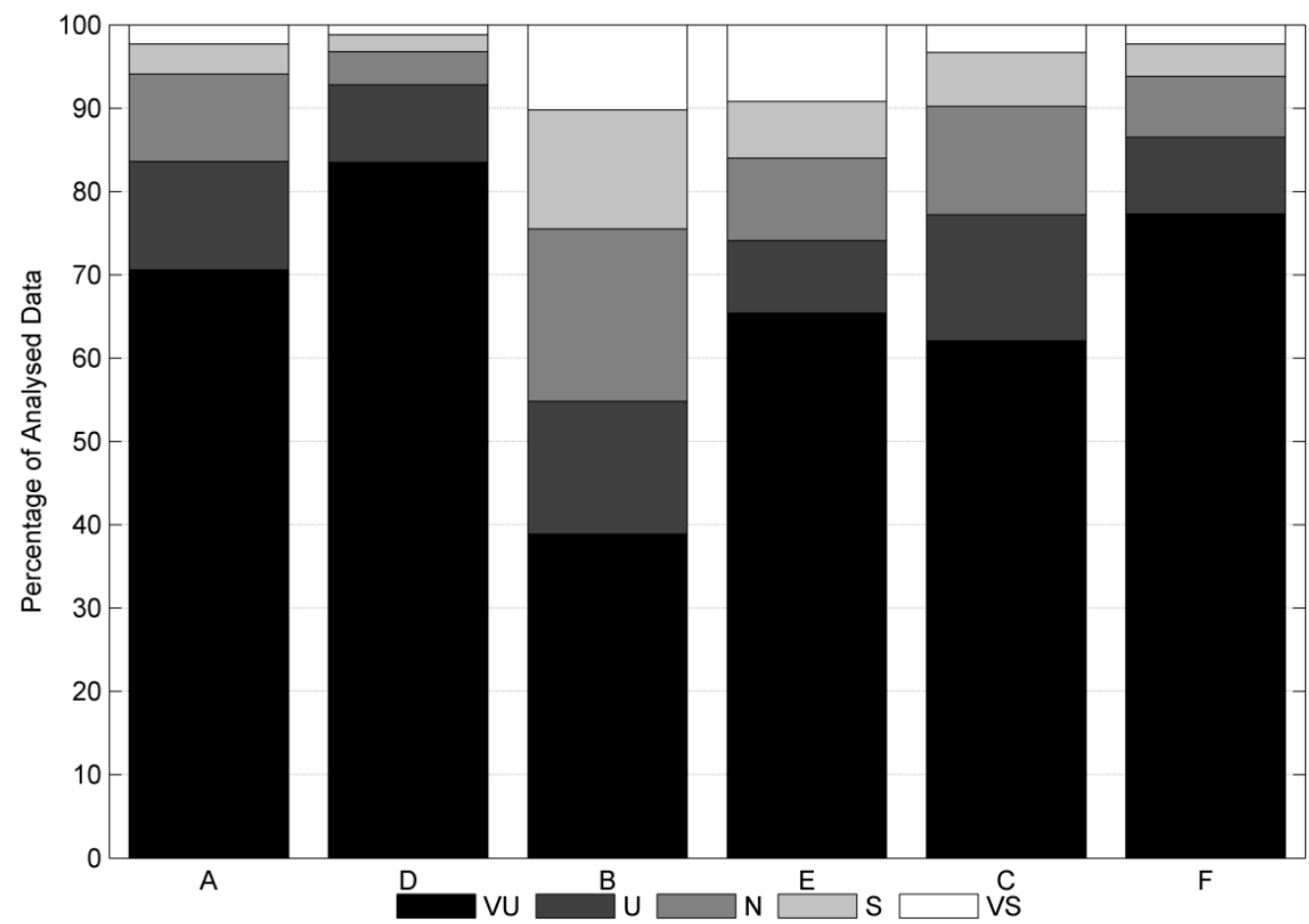

Figure 1 Distribution of stability for each case study dataset.

For the purpose of comparison between alternative methods of calculating the atmospheric stability; Figure 2 below plots the distributions for Cases A, B and C from FINO1 alongside distributions publicised by [11] from the same offshore mast utilising the sonic anemometers to calculate $L$ via both flux and bulk Richardson number approaches. As the sonic data comes from after the construction of the Alpha Ventus wind farm, it had been filtered by wind direction to avoid wake 
interference. Therefore, data from Cases $A, B$ and $C$ have been filtered to maintain directional consistency, although the data collection period differs by three years.

Comparing the five stability distributions indicates that the gradient method returns greater proportions of VU events than either the flux or bulk methods. However Case $\mathrm{B}$, utilising measurements from the upper mast portion, is in close agreement with the flux method, despite its reference height being located over $25 \mathrm{~m}$ higher up the mast. By comparison, the distribution of Case $A$ is considerably more unstable than either of the results from [11], despite having a reference height less than a single metre apart. Case $C$ with its reference height $15 \mathrm{~m}$ higher, also shows a greater frequency of VU events than either of the flux of bulk methods, although its proportion or $\mathrm{U}$ and $\mathrm{N}$ events is similar to those of the bulk method. The differences between results suggest the height at which measurements are made is more significant to the gradient method than its resulting reference height.

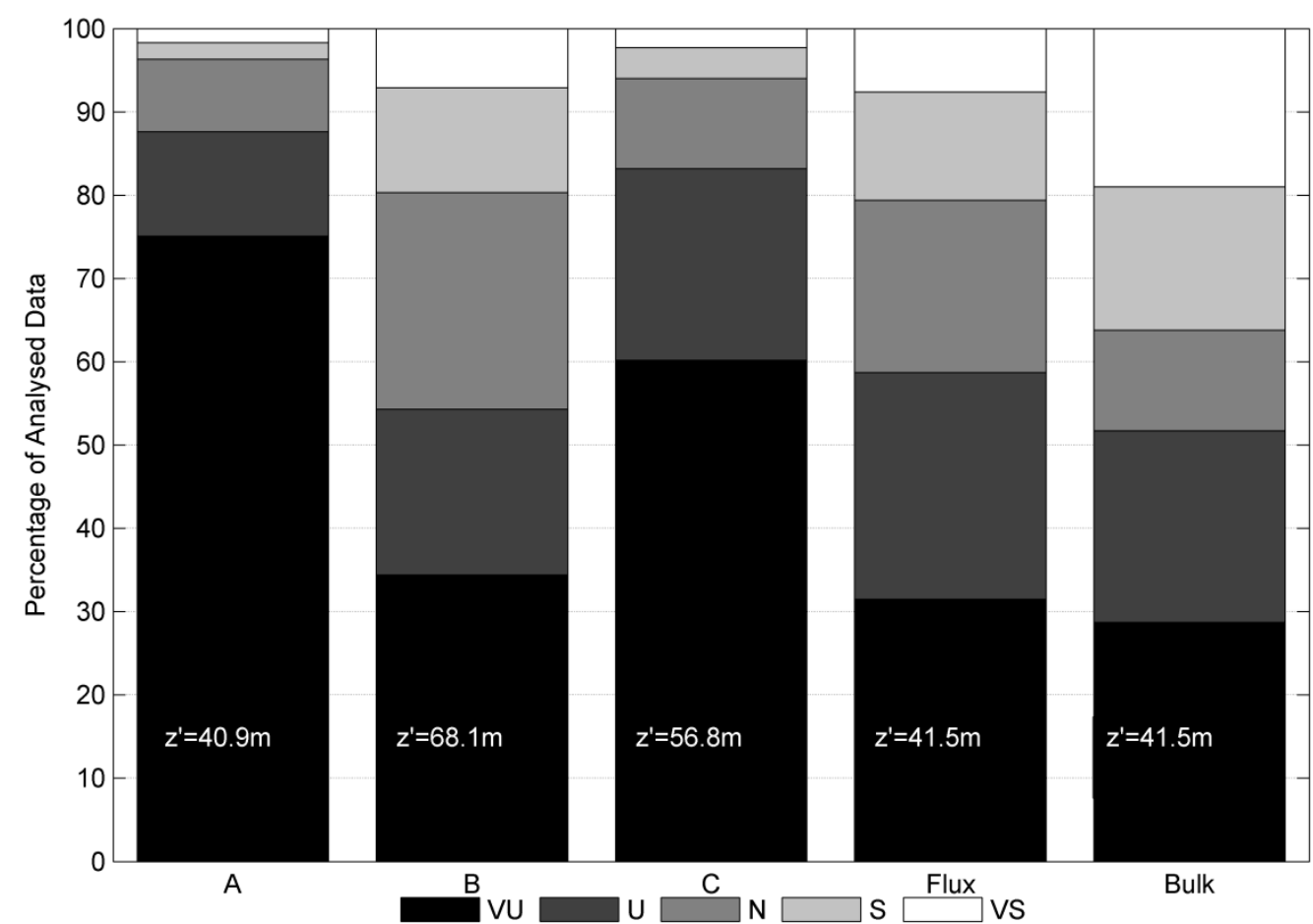

Figure 2 Distribution of stability at FINO1 as calculated via the gradient method, compared alongside results from reference [11] using their flux and bulk methods. For consistancy with [11], Cases A, B and $C$ have been filtered by wind direction to only include the sector $240^{\circ}-360^{\circ}$.

To further investigate this point, Figure 3 shows the mean VPT profiles for each site and as a function of wind direction. Below $50 \mathrm{~m}$, the stronger gradients suggest greater instability than above $50 \mathrm{~m}$, although seasonal variability and weather systems result in the standard deviations of each sample to be roughly 5 degrees. This means there is no clear statistical confidence that the VPT is non-linear with height, however with only 3 reference points, the height of those reference points is important for our understanding of the local atmospheric stability. For example, if the middle height VPT values were instead derived from measurements just $10 \mathrm{~m}$ higher up the mast, $A$ and $D$ may show a higher proportion of stable events. Similarly, if the heights of the lowest values were actually $10 \mathrm{~m}$ lower on the mast, $A, D, C$ and $F$ might all produce more unstable results, assuming the VPT is linear with height below $50 \mathrm{~m}$ and also above $50 \mathrm{~m}$. This is an assumption which is only maintained by the high variance in temperature measurements, despite qualitative indications from 
distributions and filtering due to high Richardson numbers in Figure 1 suggesting a non-linear profile.

Typically for Western Europe, the northerly and easterly winds are colder than the average, although the difference is significantly greater at FINO3 despite being twice the distance from shore and therefore experiencing a greater influence from the large heat capacity of the sea. Worth noting is the difference in range of VPT by wind direction at each site considering they are roughly $130 \mathrm{~km}$ apart. Although the large variances mean the differences are not statistically significant; any directional variation that does exist may be partially due to a shorter easterly fetch for FINO3 (and so greater variation from site average). Although following this argument, FINO1 should experience higher temperatures for southerly winds yet Figure 3 does not support this theory. Therefore, it is assumed that variation in absolute VPT between sites is a result of mast data recorded over different time periods.
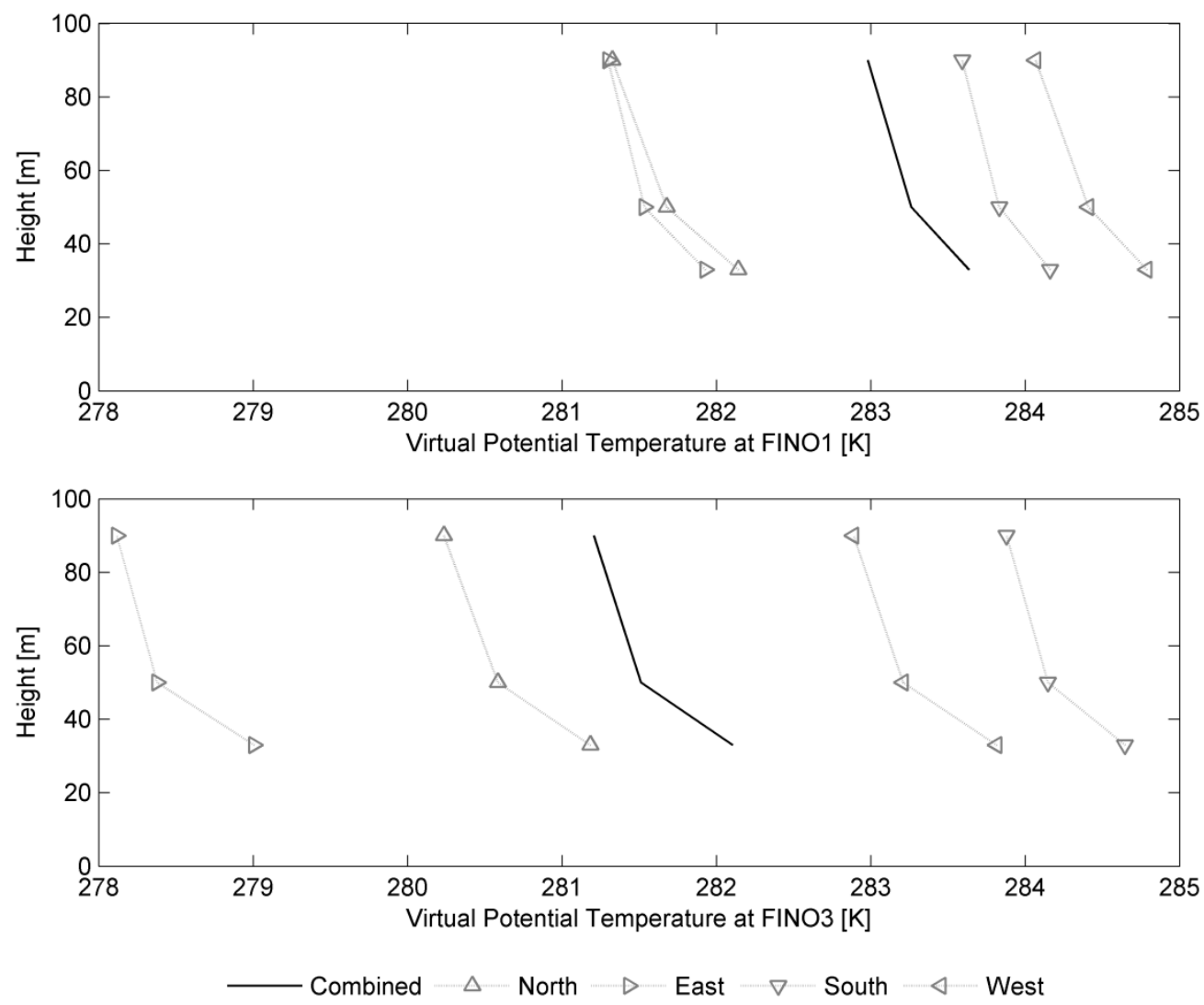

Figure 3 Virtual potential temperatures at FINO1 (top) and FINO3 (bottom) by direction sector.

The variation in temperature shown in Figure 3 suggests a loose relationship to sea surface temperature. Although measured, no water measurements were available for analysis. It is, therefore, hypothesized that water's relatively larger heat capacity would lead to little variation in temperature with wind direction. It appears possible that at heights greater than $30 \mathrm{~m}$ above the sea, perhaps on account of low surface roughness values, horizontal advection of air parcels from other regions may have a more direct impact on stability than the sea itself. Although beyond the scope of this work, it is worth considering that while higher wind speeds lead to greater sea surface roughness values, both increased roughness and surface temperature will result in increased VPT at lower levels as a result of increased relative humidity. 
The results presented in Figure 4 make use of the more extensive absolute temperature measurements at FINO1 to further investigate the nature of temperature in the marine SL. Whilst sample standard deviation values again mean there is no statistical difference between wind direction or measurement height, measurements from all wind directions suggest there may be some atmospheric feature which although requiring more detailed data filtering to decisively prove, may impact any stability calculations from individual measurements rather than as an average across a large time scale.

If it exists as more than a statistical quirk of a dataset with seasonal variability, the implied difference in temperature profile between $40 \mathrm{~m}$ and $50 \mathrm{~m}$ could be caused by a number of reasons, but since the FINO1 project team calibrates and deploys its instruments to a high scientific level [15] it is unlikely to be from systematic measurement errors at either height. Therefore, it is hypothesised that the rapid change in temperature gradient is caused by a persistent internal boundary layer. Comparing profiles for easterly and westerly winds implies that this internal boundary layer height does not change with distance from shore as all directions maintain an average $40 \mathrm{~m}$ absolute temperature roughly $0.3 \mathrm{~K}$ greater than at $50 \mathrm{~m}$. Since FINO3 only measures temperature at three heights, a plot of absolute temperature profiles is not shown as it would not expand on results from Figure 3. Such indicators of internal boundary layers as shown in Figure 3 and Figure 4 show the significance of additional measurement heights for resource assessment, either to incorporate redundancy, highlight suspicious measurements or reveal atmospheric structures that may contradict the standard modelling assumptions.

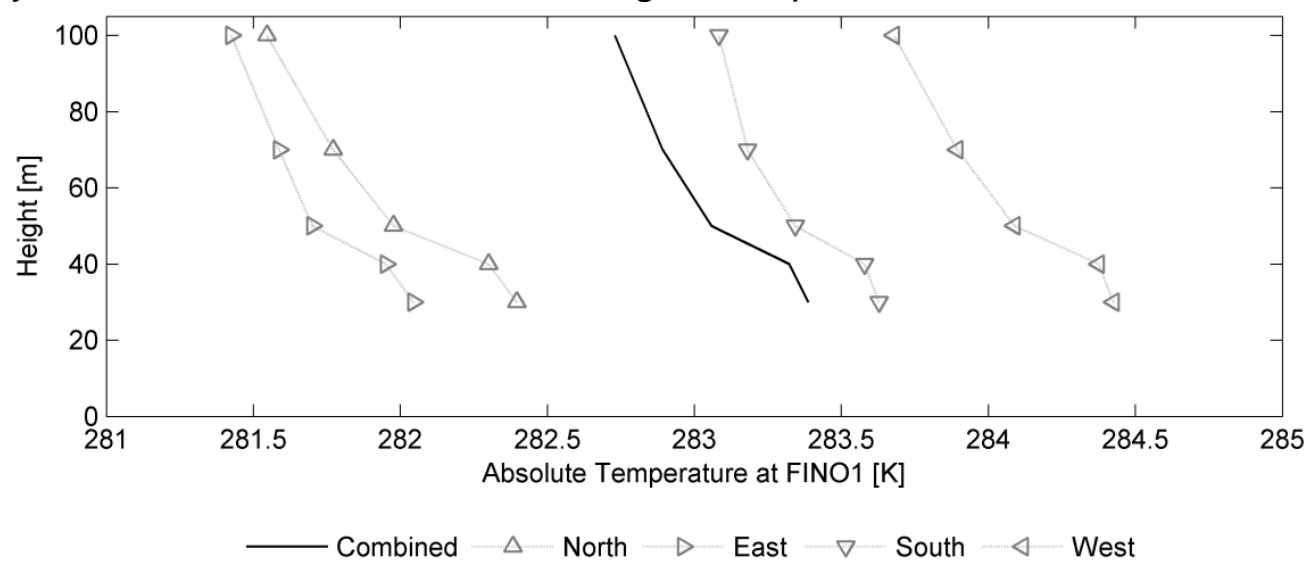

Figure 4 Absolute temperature profiles at FINO1 by direction sector.

The thermal state of the atmosphere will strongly affect the levels of ambient turbulence, and therefore wind turbine wake behaviour, but only under more stable conditions will it significantly affect the wind shear profiles at hub height. Figure 5 shows wind speed profiles for all categories $(A-F)$ under the five stability conditions. In very unstable conditions (as defined individually by each method), the average wind speeds for each mast never vary more than $0.6 \mathrm{~m} / \mathrm{s}$ throughout measured profile heights. The same is generally true for the unstable cases although $\mathrm{B}$ and $\mathrm{E}$ both display higher average speeds than the others at lower levels. Ignoring the difference in absolute wind speeds between masts, all six profiles display wind shear characteristics of unstable and very unstable conditions, with negligible shear in the very unstable case and slight shear in unstable conditions. It should be noted that under unstable conditions, E displays a profile sheared less than the others whilst B displays a lower average wind speed at $100 \mathrm{~m}$ then at $90 \mathrm{~m}$. 
Under neutral conditions, Figure 4 shows greater variation between $A-C$ and also D-F. Whilst $A, C, D$ and $F$ display similar profiles varying by roughly $1 \mathrm{~m} / \mathrm{s}$ for each mast, $B$ and $E$ display shear profiles more characteristic of an unstable atmosphere. The precise reason for this is unclear although it is likely that as their ratios of thermal to mechanical shear are small enough to result in neutral values of $L$, and the wind shear is small, it follows that there is a negligible thermal shear. As this is only apparent higher up the mast (Cases B and E), it is reasonable to conclude the upper mast is subject to less variation in air temperature (as shown in Figure 3), possibly with the lower air dampening any effects of variable surface forcing. In stable conditions, all six profiles again show the same shear, but the absolute difference between the $A, B$ and $C$ as well as $D, E$ and $F$ have become significant. For example, at FINO3 under stable conditions, the average wind speed at $30 \mathrm{~m}$ varies by up to $2.5 \mathrm{~m} / \mathrm{s}$ depending on the height at which stability is calculated, whilst the difference in average wind speeds exceed $3 \mathrm{~m} / \mathrm{s}$ at FINO3 when very stable conditions are considered. The same cannot be said about FINO1 whose averaged profiles always remain within $2 \mathrm{~m} / \mathrm{s}$ of each other and indeed are in greater agreement during very stable than stable conditions.

It should be noted that in very stable conditions, A and D (as well as for D in stable conditions) show a clear decrease in shear at upper levels. It is hypothesised that this is because the SL height decreases in more stable conditions and since these categories do not contain stability data calculated from measurements above $50 \mathrm{~m}$, well below the profile anomalies, the upper mast extends significantly above the surface layer. Thus measurement heights used to calculate stability are significant, for calculating expected wind speeds, and also wind shear above hub height which is an important factor in the generation of wake turbulence and wake recovery. 

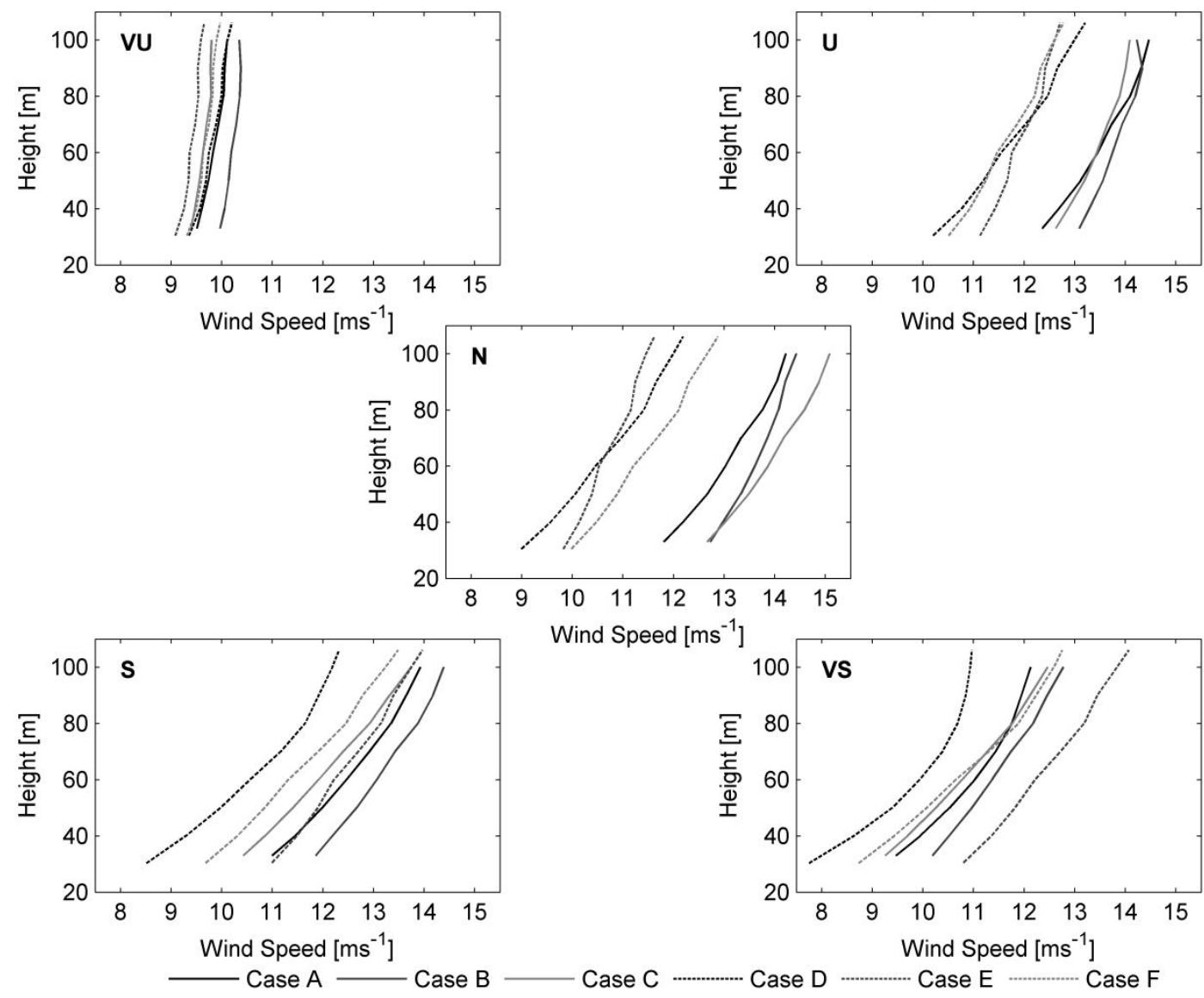

Figure 5 Wind speed profiles under different atmospheric conditions - top left $=$ very unstable, top right $=$ unstable, centre $=$ neutral, bottom left $=$ stable, bottom right $=$ very stable. Solid lines show profiles from FINO1, while dotted lines represent FINO3 profiles.

Having analysed how using different heights can change the distribution of stability and wind profiles in the SL; we also consider how the measured data in each category A-F match the wind speeds predicted by MOST. Expected speed ratios are calculated via equation 5 using the different heights relevant for each Case as a function of stability. Suitable values of $\psi_{m}(z / L)$ are calculated via the Businger-Dyer formulation [16], with $z_{0}$ assumed to be the constant value $0.0002 \mathrm{~m}$. Whilst higher wind speeds will result in larger waves leading to greater surface roughness, reference [8] has shown constant values of $z_{0}$ to be a close fit to more complex calculation methods and Table 4 shows wind speed ratios calculated using a range of values to be within $5 \%$ of the $z_{0}=0.0002 \mathrm{~m}$ results:

$$
\frac{U_{1}}{U_{2}}=\frac{\left[\ln \left(\frac{Z_{1}}{z_{0}}\right)-\psi_{m}\left(\frac{Z_{1}}{L}\right)\right]}{\left[\ln \left(\frac{Z_{2}}{z_{0}}\right)-\psi_{m}\left(\frac{Z_{2}}{L}\right)\right]}
$$

Table 4 Variation in vertical wind speed ratio across different stability conditions, as calculated using equation 5, expressed as a percentage difference from values obtained using the standard $\mathrm{z}_{0}=0.2 \mathrm{~mm}$. Values of $10 / L$ have been partitioned into bins based on one decimal place.

\begin{tabular}{|c|c|c|c|c|c|c|}
\hline \multirow{2}{*}{$10 / L$} & \multicolumn{3}{|c|}{$z_{0}=0.1 \mathrm{~mm}$} & \multicolumn{3}{c|}{$z_{0}=1 \mathrm{~mm}$} \\
\cline { 2 - 7 } & $U_{50} / \bigcup_{30}$ & $U_{90} / \bigcup_{50}$ & $U_{90} / \bigcup_{30}$ & $U_{50} / \bigcup_{30}$ & $U_{90} / \bigcup_{50}$ & $U_{90} / \bigcup_{30}$ \\
\hline-0.2 & $0.1 \%$ & $0.1 \%$ & $0.2 \%$ & $-0.4 \%$ & $-0.3 \%$ & $-0.7 \%$ \\
\hline
\end{tabular}




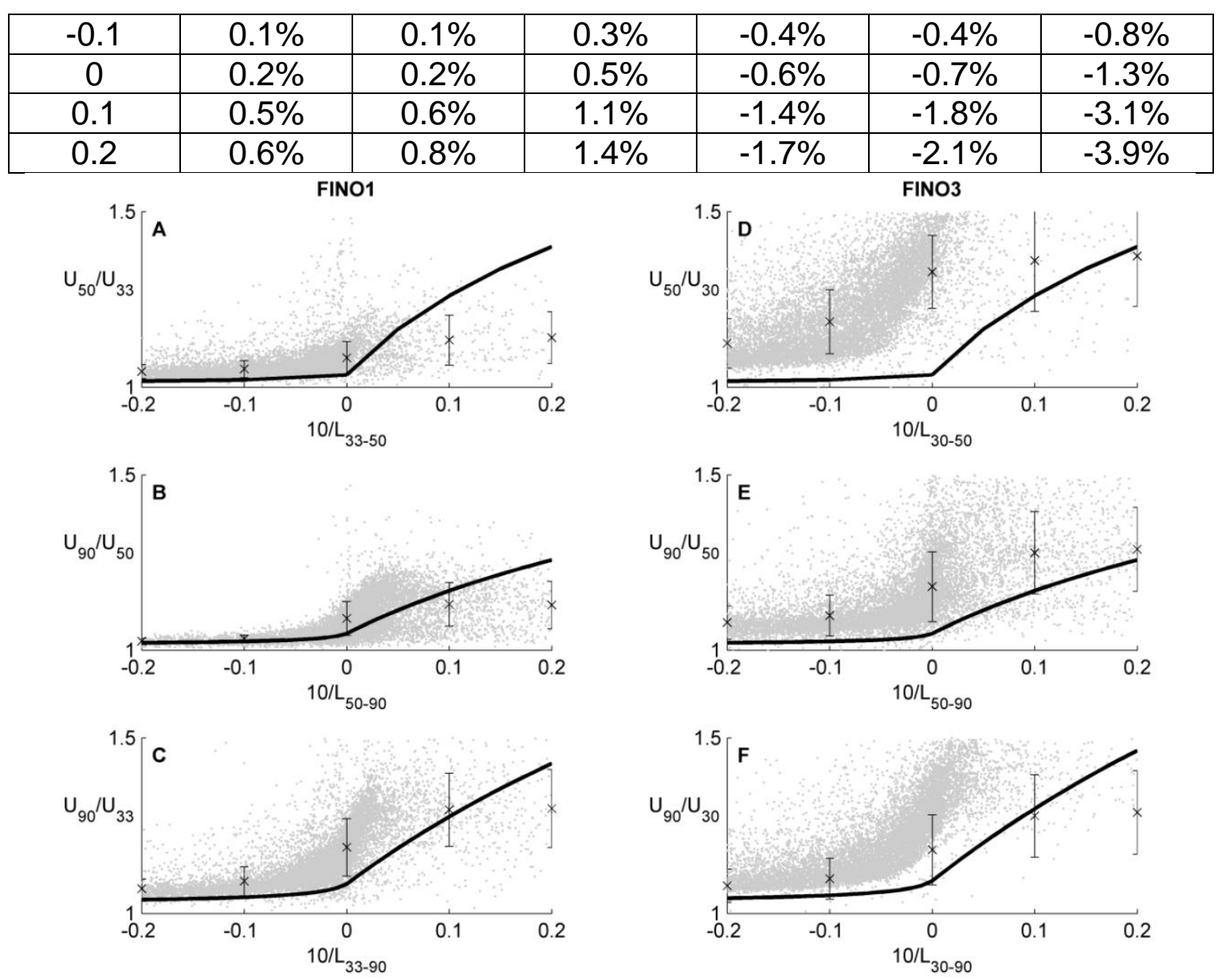

Figure 6 Scatter plots comparing the ratios of wind speeds at FINO1 (left) and FINO3 (right) at heights indicated on the left axis against corresponding predicted ratios (black lines) using equation 5 . Binned average values are shown as crosses with error bars signifying \pm 1 standard deviation about each bin.

An initial observation from Figure 6 confirms the results in Figure 1 in that there are very few very stable events $(0.05<10 / L)$ with case $B$ displaying a greater percentage than the others. None of the six case studies however can claim that MOST accurately predicts wind shear for the more stable events. Whilst the upper mast cases ( $B$ and $E$ ) have most events in this category, there is still significant scatter with MOST over predicting shear at FINO1 and under predicting at FINO3. This is due to an increase in shear values measured in each case for negative values of $10 / L$, rather than within the expected neutral range around $10 / L=0$, indicating equation 4 may produce absolute values of $R i$ which are too large in unstable events and too small in stable events. Neutral shear events at FINO1 are predicted well for case $B$ by MOST, although for cases $A$ and $C$, the value calculated using MOST reflects measurements more commonly found with Very Unstable events. This slight under-prediction of neutral shear at FINO1 along with clear under-prediction for FINO3, is consistent with the calculation of $R i$ using equation 4 , as the general shape of the measured shear scatter distribution is similar to the expected values, but with higher than expected shear. For very unstable cases $(-0.05>10 / L)$, MOST provides a good prediction of wind shear at FINO1, particularly for case B. However at FINO3, MOST consistently under-predicts the levels of shear, with mast data displaying a wide scatter, especially lower down the mast for case D. Although the structure of availability data (for example no water temperatures) led to this study using the gradient method of calculating $L$; it is worth remembering that other 
methods do exist, though reference [8] for example found similar trends across three separate approaches, the gradient method returned the largest errors but lowest variance within the stable region. As developers frequently use temperature gradients for simplicity to infer stability, their further academic study is recommended, especially comparison with other approaches.

Further investigation into the accuracy of MOST can be conducted by using equation 5 to calculate $z_{0}$ for known wind speed gradients across a range of stability values. Having calculated $L$ using equations 3 and 4, Table 5 below shows the mean values for the corresponding values of $z_{0}$ across the same stability grouping used in Table 4 and Figure 6 . Although the values are larger than the $0.0002 \mathrm{~m}$ length used in calculating the expected speed ratios in Figure 6; there is a strong inverse correlation (greater than -0.9) between the height of $z^{\prime}$ and $z_{0}$, indicating the mixing from mechanical influences such as surface roughness are most significant near the surface. Across the range of stabilities, $z_{0}$ also appears to be most significant for events with Neutral stability as these have the largest calculated values which is consistant with the physical interpretation of $L$.

Table 5 Average values of $z_{0}$ (in $\mathrm{m}$ ) for each Case across the specified stability gates.

\begin{tabular}{|c|c|c|c|c|c|c|}
\hline $10 / L$ & Case A & Case B & Case C & Case D & Case E & Case F \\
\hline-0.2 & 0.3348 & 0.1207 & 0.3127 & 0.2094 & 0.1502 & 0.0951 \\
\hline-0.1 & 0.4487 & 0.1504 & 0.2972 & 0.3580 & 0.1815 & 0.2176 \\
\hline 0 & 0.6632 & 0.2641 & 0.3001 & 0.8089 & 0.3888 & 0.3273 \\
\hline 0.1 & 0.7857 & 0.1047 & 0.2517 & 0.5950 & 0.0631 & 0.0885 \\
\hline 0.2 & 0.3290 & 0.0334 & 0.0049 & 0.1122 & 0.3318 & 0.0104 \\
\hline
\end{tabular}

To help ascertain the cause of the variation in MOST accuracy between FINO1 and FINO3, the data in Figure 6 is filtered by wind speed range. Figure 7 show these filtered data as three wind speed categories, high $\left(u>14 \mathrm{~ms}^{-1}\right)$, intermediate $\left(8<\mathrm{u}<14 \mathrm{~ms}^{-1}\right)$ and low $\left(\mathrm{u}<8 \mathrm{~ms}^{-1}\right)$. 

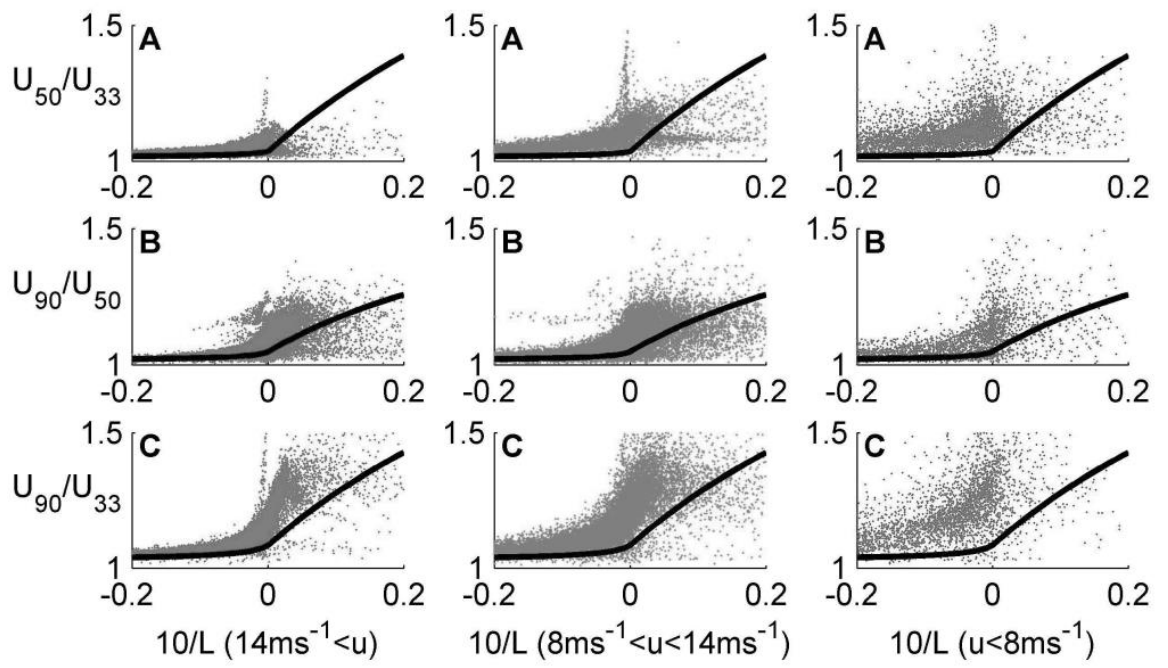

FINO3
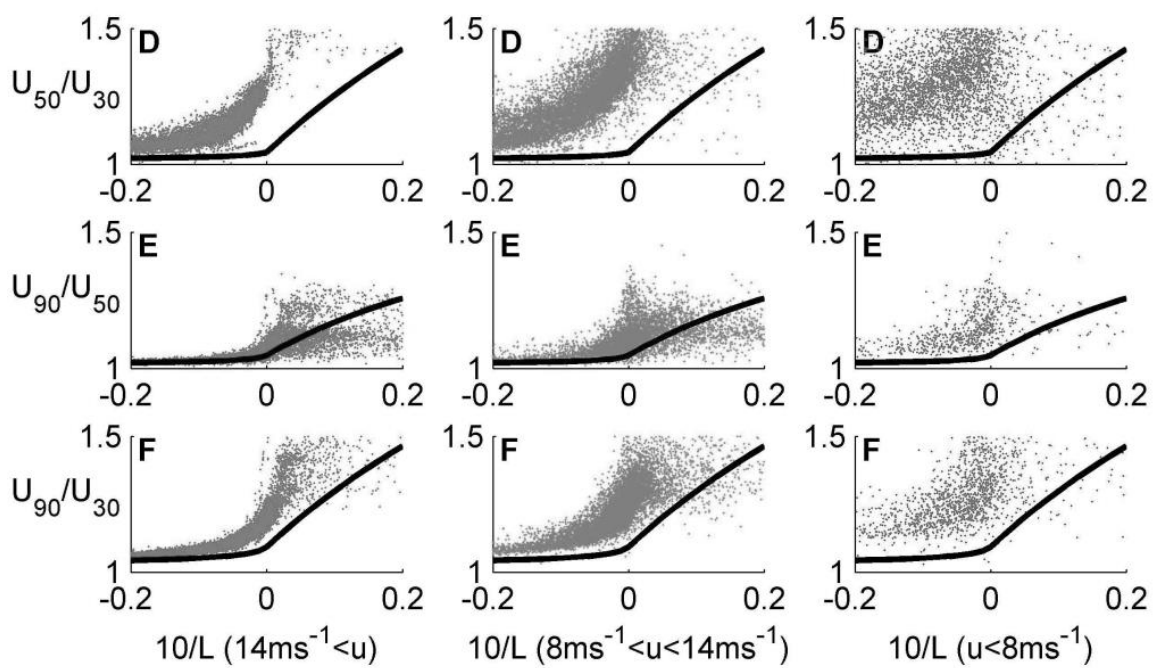

Figure 7 Scatter plots as shown in Figure 6 broken down by wind speeds as measured at the top of the two anemometers, with high wind speed $\left(u>14 \mathrm{~ms}^{-1}\right)$ events on the left, low $\left(u<8 \mathrm{~ms}^{-1}\right)$ wind speed events on the right and intermediate wind speed $\left(8<u<14 \mathrm{~ms}^{-1}\right)$ events in the centre.

Due to the filtering in Figure 7, the levels of scatter and therefore accuracy of MOST in predicting the wind shear is clearly shown to be directly linked to wind speed. In all six case studies, the events with low wind speeds have higher levels of scatter than those with high wind speeds with intermediate wind speeds resulting in mid-range levels of scatter. At FINO1 (top nine plots in Figure 7), in addition to reducing scatter, comparing higher wind speed events against MOST also results in more accurate predictions of average wind shear values from very unstable (low shear events) to very stable (high shear events). Whilst it is not clear if the same effect occurs with increasing stability for the FINO3 data (bottom nine plots in Figure 7), the higher wind speed measurements show less scatter with mean results closer to MOST predictions. This is particularly clear in case $\mathrm{F}$ which displays a clear gap between plots for MOST and measured data for intermediate wind-speed events where $10 / L<0$; this gap is large for low wind speeds and small for high wind speeds.

The additional filtering applied in Figure 7 reveals a further feature for stable conditions. This is most clearly seen in the high wind speed plot on the left of the figure, although it is also noticeable in some intermediate wind-speed cases. Above a certain value of stability measured by $10 / L$, which we denote $\zeta$, there is little 
correspondence between the shear predicted by MOST and that determined from the measured data. Although $\zeta$ varies between cases from 0 to 0.02 , the related value of $R i$ is less than half the critical value of 0.2 where flow becomes laminar [10]. For $10 / L>\zeta$, there is little increase in maximum wind shear with increasing stability and it is hypothesised that at $10 / L=\zeta$, the SL is the same height as the top wind speed measurement. This would help explain why the phenomena is most prevalent for case studies B and $E$ whilst the effect is less for cases $C$ and $F$ which also use mast upper mast measurements as values of both $10 / L$ and shear are moderated via measurements in the less stable atmosphere below. Another result of filtering by wind speed range is the revealing of narrow spikes in shear around neutral stability, seen clearest in case $A$. This is thought to be related to large variation of $\Delta u$ at low mast heights in equation 4 as they are clearest when speeds at $33 \mathrm{~m}$ are used from FINO1.

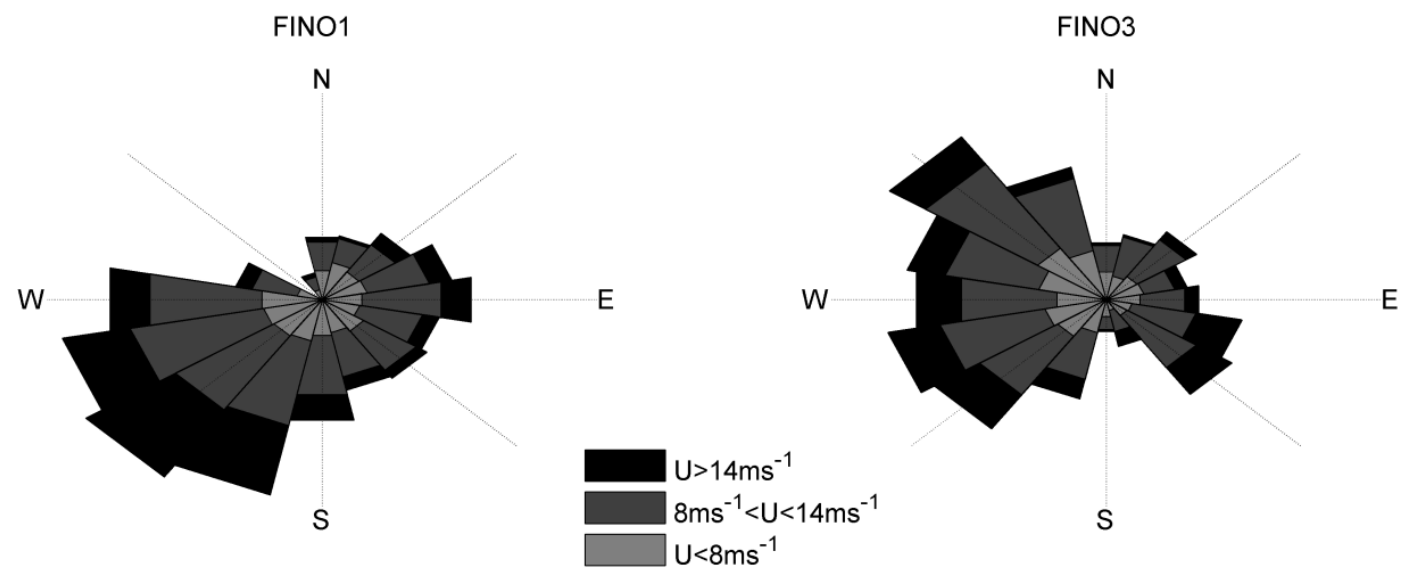

Figure 8 Wind Roses for FINO1 (left) and FINO3 (right). The rose for FINO1 clearly shows the effect of filtering to account for mast shadow over a large sector around $310^{\circ}$ whilst the FINO3 rose appears less effected by shadow as the narrow filtering does not occupy a whole segment at $170^{\circ}$.

Figure 8 shows wind roses for the two offshore masts, using directions measured with the highest available wind vane and subdivided with grayscale into the three speed categories used in Figure 7 . Despite being located roughly $130 \mathrm{~km}$ apart, and using data from different years, the two are similar. Considering the missing sectors for each rose to account for mast shadow, both show a spectrum of wind speeds with no sector disproportionally high or low and the majority of events occurring within the middle speed bin. Both masts show prevailing winds are from a wide westerly sector with the greatest quantity of high speed events, although filtering for mast shadow and different measurement periods hinder absolute comparisons across the distance separating the two masts. As a result of their locations in the North Sea, the majority of measured events at FINO1 are from directions less than $200 \mathrm{~km}$ from shore whilst events at FINO3 are more strongly distributed towards directions of longer fetches. 

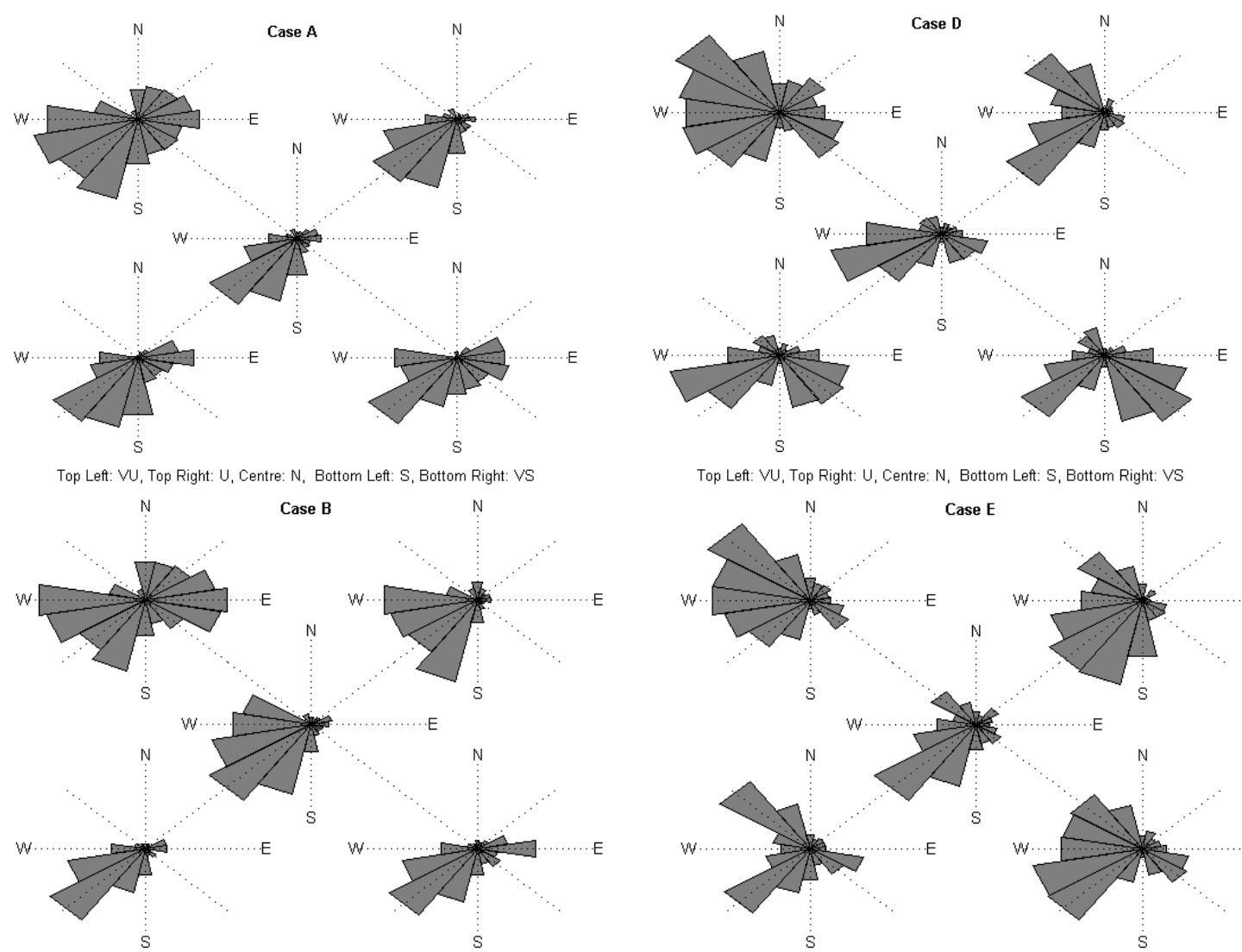

Top Left: VU, Top Right: U, Centre: N, Bottom Left: S, Bottom Right: VS

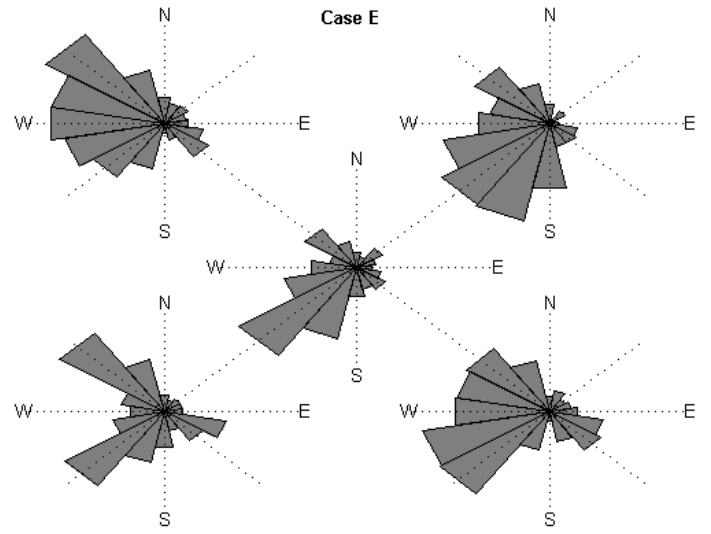

Top Left: VU, Top Right: U, Centre: N, Bottom Left: S, Bottom Right: VS
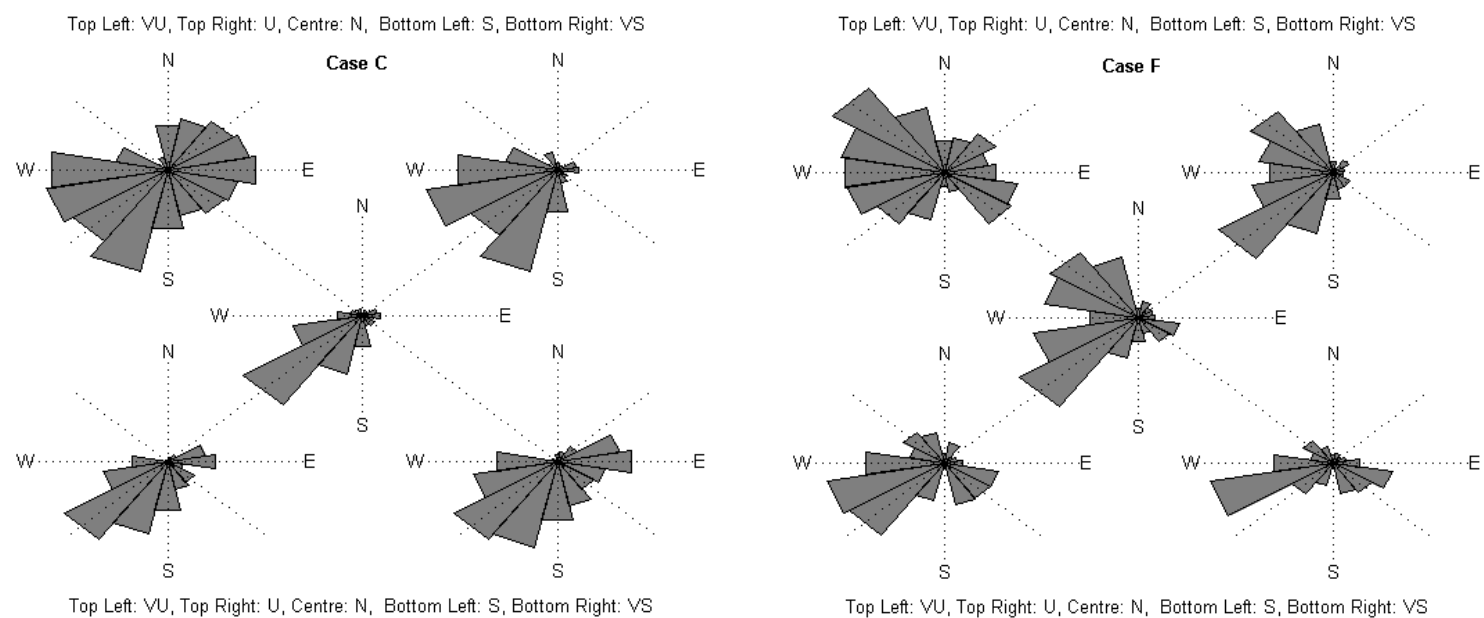

Top Left: VU, Top Right: U, Centre: N, Bottom Left: S, Bottom Right: VS

Figure 9 Wind Roses for FINO1 (left) and FINO3 (right) for each of the six case studies split into the five stability categories such that: top left: VU, top right: U, centre: N, bottom left: S, bottom right: VS. Wind directions were measured at $90 \mathrm{~m}$ and $100 \mathrm{~m}$ at FINO1 and FINO3 respectively.

Whilst Figure 8 suggests the proportions of North Sea wind speeds below $14 \mathrm{~ms}^{-1}$ to be evenly distributed relative to directional frequency, Figure 9 shows atmospheric stability to be strongly dependent on wind direction. For example, almost all events at FINO1 from the northerly quarter $\left(315^{\circ}>\theta\right.$ or $\left.\theta<45^{\circ}\right)$ are very unstable. Another way of analysing the roses shows unstable, neutral and stable events at FINO1 are primarily from the southwest quadrant $\left(180^{\circ}<\theta<270^{\circ}\right)$ whilst the more extreme stability categories vary more in direction. It is worth noting that neutral events at FINO1 are mostly concentrated in a few direction sectors. Combining observations from FINO1 in Figures 1 and 9 suggest that wind farm developments near FINO1 can assume predominantly very unstable conditions from most directions, particularly with respect to heights below $50 \mathrm{~m}$. Also worth noting is how the 
distribution of mast top wind directions for neutral events changes veer with stability reference height. For example, neutral events for case B using stability measurements from the upper mast shows events occur across a $90^{\circ}$ compass sector from SSW to WNW whilst neutral events for case A occur mainly from $S$ to WSW. Similarly, the unstable roses also show veering with height, with compass wind directions in case A ranging from $S$ to WSW whilst the case B rose is weighted between SSW and W. Whilst veering with height is often a result of the Ekman spiral, the difference in stability reference heights between cases $A$ and $B$ is small relative to the boundary layer depth and direction change is small; thus it is more likely the differences in results from FINO1 are caused by the underlying stability reference heights for each Case for calculating $L$ occurring within separate atmospheric sublayers and the resulting classification by stability. The inclusion of stability measurements from lower down the mast as in both case $A$ and $C$ result in less variation in wind directions with a greater dominance from the southwest sector. The reverse is true for unstable events; where only stability measurements from the lower mast are considered (case A), the spread of events is concentrated in a fewer direction sectors than for either case $\mathrm{B}$ or $\mathrm{C}$ where upper mast stability measurements are analysed. It is unclear whether this variability in prominent directions is a direct result of differences in measurement height or a product of variable sample size for each stability category, itself a product of the stability reference height as shown by Figure 1.

The roses displaying results from FINO3 in Figure 9 are less unidirectional than those for FINO1. Although the two roses in Figure 8 are similar, and the three less extreme stability categories are still weighted towards the southwest; some roses show greater influence from wider sectors compared to their FINO1 equivalent. Others show high frequencies from the northwest (where mast shadowing affected FINO1 results). An example of this is the stable rose for case $\mathrm{E}$, while its equivalent for case B is weighted strongly to the southwest. Neither of the other stable events for FINO3 case studies (with stability reference heights lower down the mast) show this directional spike, with each indicating stable events are more commonly occurring with south-easterly winds. Lower stability reference heights on the mast may indeed result in more unstable characteristics as the dominant northwest sector appearing in the stable rose for case $\mathrm{E}$ may include the same events as the clear northwest sector for the neutral category for case $F$ or even the unstable rose in case $D$. The wide sector of west to northwest directions for the very stable category of case $E$ is also missing from the roses categorised using stability measurements from lower heights in cases $D$ and $F$. Thus, whilst variable sample sizes of each stability category make direct comparisons difficult, variation in stability reference height can significantly change not only the categorising of stability events, but also the significant wind direction, which will have implication for both initial wind resource and wind turbine array wake loss predictions for a proposed offshore wind farm. 


\section{FINO1}
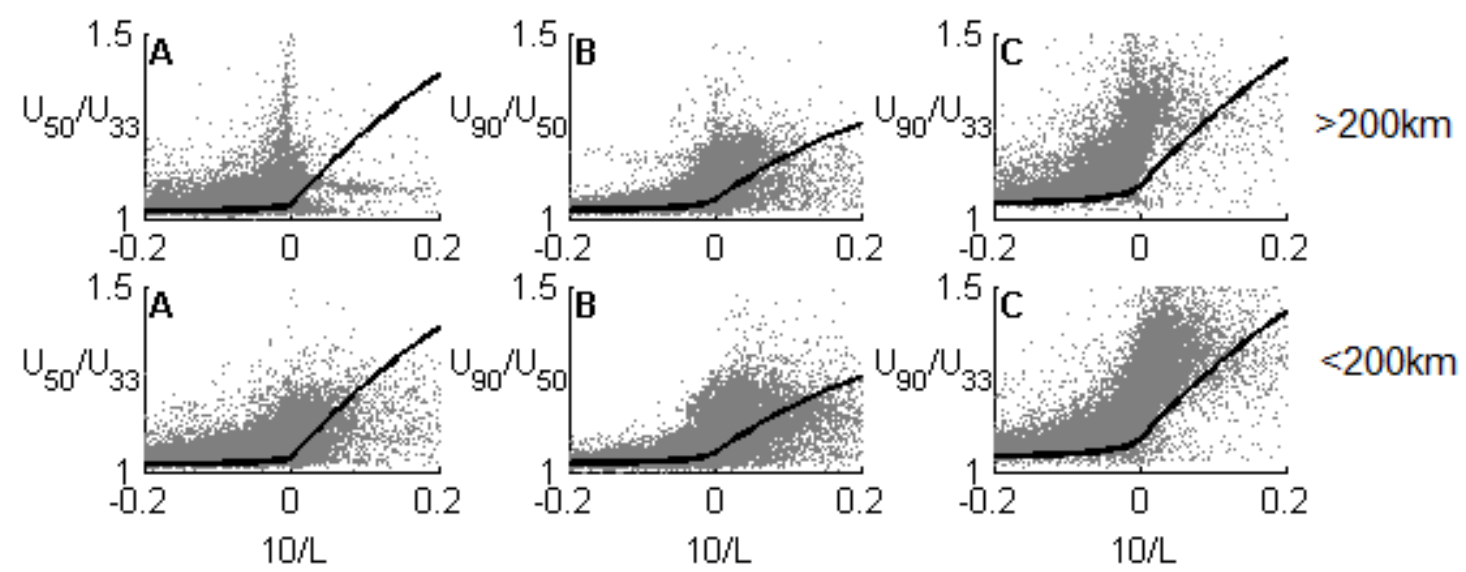

FINO3

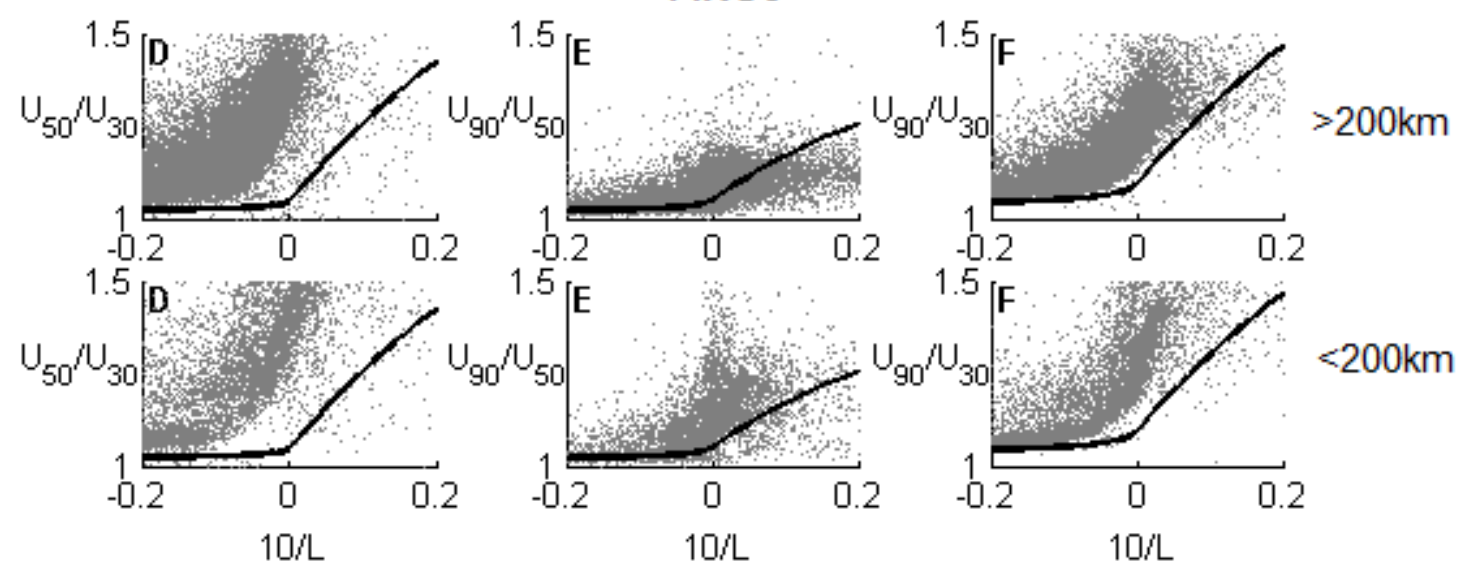

Figure 10 Scatter plots as in Figure 6 split into directions with a longer offshore fetch (>200km) and shorter offshore fetch $(<200 \mathrm{~km})$ as measured by the wind vanes at the top of each mast. The black lines show the MOST expected shear values.

With the arbitrary definition of a long offshore fetch being greater than $200 \mathrm{~km}$, Figure 10 compares measurements from directions with long offshore fetch against directions with shorter fetch. Whilst FINO1 and FINO3 are located $40 \mathrm{~km}$ and $80 \mathrm{~km}$ from the nearest shore respectively, there are still some variations in shear depending on fetch. For example, whilst the overall range of shear values measured in case $\mathrm{F}$ does not noticeable vary, the dense region of points indicating high frequency is narrower for shorter fetch directions than for the longer marine fetches. This is also seen for case $D$, although this may be due to the higher frequency of offshore wind cases at FINO3. Possibly due to its closer proximity to shore, the reverse is true at FINO1, where wind direction observations from coastal sectors are more frequent. However, this has not resulted in much variation in fetch dependent scatter for cases A, B or C in Figure 9 except in the region $10 / L>\zeta$ as mentioned for Figure 7.

\section{Conclusion}

This study has applied MOST to two offshore locations and generally found that the theory acceptably predicts wind shear in unstable conditions but that caution is advised when considering stable conditions, particularly for greater heights. The three year data set used from FINO1 generally supports these findings though results from the two year data set from FINO3 are less clear. Differences in results 
between masts could be due to variation in weather patterns as the data were not from consistent years. Alternatively, location may have played a part since, although the two masts are both in the North Sea, they are roughly $130 \mathrm{~km}$ apart with the nearest land in different directions, (south for FINO1 and east for FINO3). Despite being far from the coast, and both datasets suggesting the presence of internal boundary layers around $50 \mathrm{~m}$, it is seen that temperature profiles, and thus stability are vary with wind direction. This was unexpected considering the high thermal capacity of the sea. It would seem that a fetch of $80 \mathrm{~km}$ is not enough at FINO3 for the effects of the coast to be completely ignored and, along with the SL height, should be included in the resource assessment considerations for offshore wind farm projects. It is also concluded that offshore advection of air from one region to another may play a more significant role determining hub height stability than the sea surface temperature.

Although less relevant for the wind industry, the analysis reveals another consideration for MOST, i.e. around neutral stability, there is often a spike in wind shear which corresponds to low wind speeds. Therefore, caution is recommended when analysing data with very low velocities and it is hypothesised that an additional filter to remove data entries below a minimum speed could be introduced. This may result in Figure 1 displaying an even lower proportion of neutral cases. Removing low speeds from all analysis altogether is likely to decrease the dominance of very unstable events.

Having analysed the atmospheric stability using measurements from different heights at two high quality research met masts, it is clear that the height at which measurements are made is significant and influences many of the resulting conclusions. Therefore, it is recommended that masts used for resource analysis are equipped to record temperature and humidity measurements at more than three heights. Although high variance in the data prevented confirmation through statistical tests, the three heights used at FINO3 were enough to suggest that the thermal profile may not be linear as assumed by MOST, but not for showing a detailed atmospheric profile. Whilst FINO1 is equipped with temperature sensors at five heights, humidity is only measured at three, the highest of which is not situated at the same height as any temperature sensor. Multiple sensors indicated that the top of an internal boundary layer may be located between $40 \mathrm{~m}$ and $50 \mathrm{~m}$. Thus informed decisions about which instrument heights are suitable for resource assessment and a more complete picture of the structure of the atmosphere encountered by large turbines can only result from an appropriately detailed measurement campaign.

In terms of absolute shear, Figure 5 shows MOST predicts similar values for very unstable to neutral conditions irrespective of measurement height. However, for positive (stable) values of $L$, the rate of shear is very dependent on measurement height, with largest values expected lower down the mast. Furthermore, the shear levels over the whole mast are closer to those through the lower mast than the upper mast. This reinforces the finding that stability frequency distributions from the two cases using data from the entire mast height were more similar to distributions using measured data from just the lower mast heights. This would suggest that there is little need to extend mast measurements above $50 \mathrm{~m}$ as it is the lower boundary layer that appears to dominate profiles averaged across the whole mast up to hub height. However, this assumes that MOST is a reliable theory when predicting wind conditions offshore, an assumption which the variation in Figure 6 shows to be questionable, particularly in more stable conditions. Therefore, not only is it important to make wind speed measurements at least to hub height and preferably beyond, 
temperature measurements should also be made at multiple similar heights. Even for wind directions with large fetches across the North Sea, results from both masts suggest the possibility of non-linear thermal profiles in the SL, contrary to MOST assumptions. These also highlight the need for multiple measurement heights to provide redundancy and help capture the true nature of the offshore atmospheric boundary layer.

\section{Acknowledgements}

The authors would like to thank the BMU (Bundesministerium fuer Umwelt, Federal Ministry for the Environment, Nature Conservation and Nuclear Safety) and the PTJ (Projekttraeger Juelich, project executing organisation) for providing data from the FINO1 and FINO3 meteorological masts. The authors would also like to thank E.ON for sponsoring this research through an EPSRC CASE award and the EPSRC Supergen Wind Energy Technologies consortium (grant number: EP/H018662/1) for additional support.

\section{References}

[1] Motta, M., Barthelmie, R. and Vølund, P.: 2005 'The Influence of NonLogarithmic Wind Speed Profiles on Potential Power Output at Danish Offshore Sites', Wind Energy, 8, 219-236.

[2] Muñoz-Esparza, D., Cañadillas, B., Neumann, T. and van Beeck, J.: 2012 'Turbulent Fluxes, Stability and Shear in the Offshore Environment: Mesoscale Modelling and Field Observations at FINO1', J. Renewable Sustainable Energy. 4. 063136-063152.

[3] Hansen, K., Barthelmie, R., Jensen, L. and Sommer, A.: 2012 'The Impact of Turbulence Intensity and Atmospheric Stability on Power Deficits due to Wind Turbine Wakes at Horns Rev Wind Farm', Wind Energy. 15, 183-196.

[4] Argyle, P. and Watson, S.: 2012, 'A Study of Surface Layer Atmospheric Stability At Two UK Offshore Sites', Scientific Proceedings of the 2012 European Wind Energy Association Conference \& Exhibition, EWEA '12, 1619 April 2012, Copenhagen, Denmark.

[5] Peña, A., Gryning, S-E. and Hasager, C.: 2008, 'Measurements and Modelling of the Wind Speed Profile in the Marine Atmospheric Boundary Layer', Boundary-Layer Meteorol. 129, 479-495.

[6] Carney, G., Housley, P., Montavon, C. and Jones, I.: 2012, 'Practical Usage of CFD for Wake Effects Prediction Within Offshore Wind Farms', Scientific Proceedings of the 2012 European Wind Energy Association Conference \& Exhibition, EWEA '12, 16-19 April 2012, Copenhagen Denmark.

[7] Texier, O., Bezault, C., Girard, N., Houbart, J-C. and Pham, S.: 2012, 'Results of Integration of Atmospheric Stability in Wind Power Assessment Through CFD Modelling', Scientific Proceedings of the 2012 European Wind Energy Association Conference \& Exhibition, EWEA '12, 16-19 April 2012, Copenhagen Denmark.

[8] Lange, B., Larsen, S., Højstrup, J. and Barthelmie, R.: 2004, 'The Influence of Thermal Effects on the Wind Speed Profile of the Coastal Marine Boundary Layer', Boundary-Layer Meteorol. 112, 587-617.

[9] Argyle, P. and Watson, S.: 2013, 'The Influence of Measurement Height and Stability Calculation Methods for a Location in the Irish Sea', Proceedings of the 2013 European Wind Energy Association Offshore Conference \& 
Exhibition, EWEA Offshore '13, 18 November - 21 November 2013, Frankfurt, Germany.

[10] Stull, R.: 1988, 'An Introduction to Boundary-Layer Meteorology' ISBN 90277-2768-6 ed. Kluwer Publications Ltd.

[11] Cañadillas, B., Muñoz-Esparza, D. and Neumann, T.: 2011, 'Fluxes Estimation and the Derivation of the Atmospheric Stability at the Offshore Mast FINO1', Scientific Proceedings of the 2011 European Wind Energy Association Offshore Conference \& Exhibition, EWEA Offshore '11, 29 November - 1 December 2011, Amsterdam, The Netherlands.

[12] Grachev, A. and Fairall, C.: 1996 'Dependence of the Monin-Obukhov Stability Parameter on the Bulk Richardson Number over the Ocean', J. Appl. Meteorol. 36, 406-414.

[13] Fairall, C., Bradley, E., Godfrey, J., Wick, G., Edson, J. and Young, G.: 1996 'Cool-skin and Warm-layer Effects on Sea Surface Temperature', J. Geophys. Res. 101, 1295-1308.

[14] Eecen, P., Wagenaar, J., Stefanatos, N., Pedersen, T., Wagner, R. and Hansen, K.: 2011 'Final Report UpWind 1A2 Meteorology', Energy Research Centre of the Netherlands Report ECN-E--11-013.

[15] Neumann, T., Nolopp, K., Riedel, V., Strack, M., Herklotz, K., and Stein J.: 2004 'Assessment of One Year Wind Measurements on the First Offshore Wind Research Platform in the German Bight - FINO1', DEWEK 2004.

[16] Businger, J., Wyngaard, J., Izumi, Y., and Bradley, E.: 1971 'Flux-Profile Relationships in the Atmospheric Surface Layer', J. Atmos. Sci. 28, 181-189. 